\section{Parental Relationship} Status as a Moderator of the Associations Between Mothers' and Fathers' Conflict Behaviors and Early Child Behavior Problems
Journal of Interpersonal Violence

$|-3|$

(C) The Author(s) 2020

Article reuse guidelines: sagepub.com/journals-permissions DOI: | 0.1 | $77 / 08862605209485$ |4 journals.sagepub.com/home/jiv

@SAGE

\author{
Shawna J. Lee, PhD, 'D Garrett T. Pace, MSW,' \\ Joyce Y. Lee, MS, MSW, 'D and Inna Altschul, PhD ${ }^{2}$
}

\begin{abstract}
This study examines interparental conflict and associations with child behavior problems among a large, diverse sample of families with low income $(N=2,69$ I) using path model analyses of mothers' and fathers' reports of constructive interparental conflict, destructive interparental conflict, and intimate partner violence (IPV) victimization at 15 months and child emotional insecurity and child behavior problems at 36 months. Multigroup models examined whether parental relationship status (i.e., married, cohabiting, and churning) moderated these associations. Fathers' perceptions of interparental conflict behaviors showed few direct associations with child outcomes, whereas mothers' perceptions of interparental conflict showed more robust associations with child outcomes. Specifically, mother-reported destructive conflict was associated with higher levels of child emotional insecurity and child behavior problems across parental relationship status subgroups.
\end{abstract}

\footnotetext{
'University of Michigan, Ann Arbor, USA

${ }^{2}$ University of Denver, CO, USA

Corresponding Author:

Shawna J. Lee, School of Social Work, University of Michigan, 1080 South University Avenue, Ann Arbor, MI 48109, USA.

Email: shawnal@umich.edu
} 
Mother-reported constructive conflict had a small negative association with child behavior problems in cohabiting families. Child emotional insecurity mediated the association of maternal destructive conflict on child behavior problems. Although churning families experienced higher levels of moderate and severe interparental conflict, associations linking destructive conflict to child behavior problems were consistent across parental relationship subgroups. There were few direct effects of father-reported constructive and destructive conflict on child well-being. However, the results supported the notion that fathers play an influential role in the family system via maternal reports of IPV victimization. Results of this study suggest that the mechanisms underlying emotional security theory, in which child emotional insecurity mediates the associations between maternal destructive conflict and child behavior problems, apply to a large and racially diverse sample of socioeconomically disadvantaged children.

\section{Keywords}

domestic violence, interparental conflict, Emotional Security Theory, interpersonal violence, Building Strong Families

In $2017,41 \%$ of all births in the United States were to unmarried women (Martin et al., 2018). Although most unmarried couples are cohabiting or in a relationship at the time of their child's birth, relatively few go on to marry (Carlson et al., 2008). One of the key insights gained from the Fragile Families and Child Wellbeing Study (FFCWS) is that there is a high degree of relationship instability among parents with low income who are unmarried at the time of their child's birth. The term churning refers to relationships in which individuals are in an on-again and off-again relationship with the same partner (Turney \& Halpern-Meekin, 2017). In the FFCWS, in the first 5 years of their child's life, about $42 \%$ of unmarried parents were consistently together, $16 \%$ reported relationship churning, $14 \%$ were stably broken up, and $27 \%$ had repartnered (Turney \& Halpern-Meekin, 2017). The dynamics of relationship churning are unique in comparison to being in a stable partnership (e.g., married or cohabiting for multiple waves of data collection) or being stably broken up. When compared with parents who were stably married or cohabiting, relationship churning was associated with higher levels of parenting stress (Halpern-Meekin \& Turney, 2016) and higher rates of maternal-reported intimate partner violence (IPV) (Halpern-Meekin \& Turney, 2018).

This study examines mothers' and fathers' reports of constructive conflict, destructive conflict, and IPV as predictors of child emotional insecurity and child behavior problems. The primary research question is whether mothers' 
and fathers' reports of interparental conflict differ in their associations with child outcomes. Building from Emotional Security Theory (EST; Davies \& Martin, 2013; Davies \& Sturge-Apple, 2007), we examine whether child emotional insecurity mediated associations between interparental conflict and child behavior problems. The study focuses on socioeconomically disadvantaged families which tend to experience higher rates of interparental conflict and IPV (Masho et al., 2019; Stith et al., 2004). We also examine the associations of interparental conflict to child behavior problems in married, cohabiting, and churning family configurations.

\section{EST}

Exposure to interparental relationship conflict, including destructive conflict (e.g., nonverbal anger, withdrawal behaviors; Cummings et al., 2003) and IPV (e.g., hitting, slapping; Straus et al., 1996), is associated with children's poorer socioemotional development and behavior problems (Cummings \& Davies, 2010; Evans et al., 2008; Harding et al., 2013). EST (Davies \& Martin, 2013; Davies \& Sturge-Apple, 2007) provides one framework for understanding how interparental conflict contributes to negative outcomes for children. EST proposes that child emotional insecurity is a key mediator of the linkages between interparental conflict and child behavioral outcomes (Cummings \& Davies, 2010; Davies et al., 2012; El-Sheikh et al., 2008). Specifically, exposure to destructive interparental conflict is hypothesized to lead to higher levels of child emotional insecurity, which contributes to the development of child externalizing behavior problems. There are three underlying components of children's emotional security: emotional reactions, behavioral dysregulation, and internal representations (Davies \& Martin, 2013). The emotional insecurity measure used for this study focuses on two of these factors: emotional reactions and behavioral dysregulation.

One aspect of EST is that it considers the role of both destructive and constructive interparental conflict strategies, and thus provides a more complete picture of parents' conflict strategies. Constructive conflict is manifested in behaviors, such as providing support and respect to one's partner during a disagreement, respecting the partner's position, problem solving, and maintaining humor or affection during disagreements. Children who are exposed to constructive conflict may have a less negative emotional response to parental conflict (Brock \& Kochanska, 2016; Cheung et al., 2016; Cummings et al., 2003; Lee et al., 2019). Some research suggests constructive conflict has benefits for children (Cummings et al., 2003; McCoy et al., 2009). For example, when children are exposed to constructive conflict they are less likely to intervene in parental problems (Cummings \& Davies, 1996). 
Much of the research examining EST and related mechanisms has focused on middle-income, mostly White, families (Cummings \& Davies, 2010; Cummings et al., 2003; DuRocher Schudlich et al., 2019; McCoy et al., 2009, 2013; Warmuth et al., 2020). One study examining low-income families in the Building Strong Families (BSF) study found that most couples engaged in some form of constructive conflict (Kopystynska et al., 2017). Another BSF study found that married, cohabiting, and non-cohabiting mothers and fathers used different levels of constructive and destructive conflict (Kopystynska et al., 2020). Married mothers showed the highest levels of constructive conflict and the lowest levels of destructive conflict. The highest levels of destructive conflict were seen among non-cohabiting parents. A similar pattern was seen for fathers, with married and cohabiting fathers showing the highest levels of constructive conflict and the lowest levels of destructive conflict compared with those in non-cohabiting unions (Kopystynska et al., 2020).

However, prior studies (Kopystynska et al., 2017, 2020) did not examine churning families nor did they examine child outcomes in relation to mothers' and fathers' reports of interparental conflict. Furthermore, some prior studies have combined moderate destructive conflict (e.g., name calling, withdrawal) and severe conflict behaviors, such as IPV (e.g., hitting, slapping) into one construct (Davies et al., 2012; El-Sheikh et al., 2008; Warmuth et al., 2020), even though the two constructs measure conflict of differing levels of severity (Kopystynska \& Beck, 2018). In this study, we disaggregate mothers' and fathers' reports of destructive conflict and IPV to examine how those behaviors may differ in their associations with child behavioral problems.

\section{Father Involvement and Interparental Conflict}

Theoretical conceptualizations of father involvement underscore the importance of fathers' roles in families and highlight multiple domains in which fathers influence child well-being (Lamb et al., 1985; Pleck, 2010). Fathers' involvement in direct caregiving and nurturing behaviors can have a positive influence on child well-being (Pleck, 2010). However, not all forms of father involvement are beneficial. In one nationally representative study, $33 \%$ of mothers and $40 \%$ of fathers reported some form of IPV, including physical violence and emotional abuse, during or after pregnancy (Charles \& Perreira, 2007). Ample research shows that interparental conflict and IPV are common among parents with young children, and harmful to child well-being (Cummings \& Davies, 2010; Evans et al., 2008). Fathers' conflict behaviors are also associated with child behavior problems (Cummings et al., 2004; El-Sheikh et al., 2008; Katz \& Gottman, 1993). 


\section{The Current Study}

This study examined the associations between interparental conflict and child behavior problems using data from a racially and ethnically diverse sample of socioeconomically disadvantaged families with young children. BSF included over 5,000 low-income, mostly unmarried parents of young children (Wood et al., 2010). The first research question was to examine mothers' and fathers' reports of conflict and associations with child emotional insecurity and child behavior problems and whether these processes differ for mothers and fathers. We assessed IPV victimization, destructive conflict, and constructive conflict as separate constructs based on theory and research showing that these elements of interparental conflict measure different constructs and relate to child well-being differentially (Cummings \& Davies, 2010; Kopystynska \& Beck, 2018). Based on EST, the second research question was to examine whether child emotional insecurity mediates the effects of interparental conflict behaviors on child behavior problems. We further examined whether these processes differ for mothers and fathers. The third research question was to examine whether parental relationship status (i.e., married, cohabiting, and churning) moderated these associations based on prior research showing differing levels of IPV among these family configurations (Halpern-Meekin et al., 2013; Halpern-Meekin \& Turney, 2018). We controlled for a comprehensive set of factors that are linked to interparental conflict and child behavior problems, such as parental depression.

\section{Method}

\section{Participants}

Respondents were participants in the BSF study, a randomized controlled trial of a healthy marriage and relationship-strengthening intervention for low-income couples conducted between 2005 and 2011 across eight sites in the United States (Wood et al., 2010). Heterosexual couples were eligible to enroll if (a) both the mother and father agreed to participate in the program, (b) the couple was romantically involved, (c) the couple was either expecting a baby together or had a baby that was younger than 3 months old, (d) the couple was unmarried at the time their baby was conceived, and (e) both members of the couple were 18 years or older (Wood et al., 2012). Couples $(N=5,102)$ were recruited from hospitals, maternity wards, prenatal clinics, health clinics, and Special Nutritional Programs for Women, Infants, and Children (WIC) clinics. Data were collected at three time points. First, both parents completed a brief eligibility survey at baseline, around the time families enrolled in the BSF study. Then, two extensive telephone follow-up 
surveys were conducted 15 and 36 months after baseline. The average age of children at the 36 month telephone interview was 37 months. Among eligible families, the BSF response rate at 36 months was $80 \%$ for mothers and $69 \%$ for fathers. Comprehensive reports of study procedures and the sample are available elsewhere (Moore et al., 2012; Wood et al., 2012). The University of Michigan institutional review board considered this study of de-identified secondary data analysis as exempt from oversight.

In this study, we used a subsample of BSF families. To complete the child emotional insecurity measure, the parents had to either (a) be married, romantically involved, or in an on-again and off-again relationship, (b) live together all or most of the time, or (c) see each other at least a few times a month. We dropped families in which neither parent completed the emotional insecurity measure at 36 months $(n=1,942)$. This reduced the sample to 3,160 families. We also dropped families in which the mother reported at both baseline and 15 months that she and the father did not reside together all or most of the time $(n=394)$, which reduced our subsample to 2,766. Finally, we dropped 75 families in which either parent reported that the father had not seen their child in the past month at 36 months. Thus, our subsample can be described as families who lived together all or most of the time at either baseline or 15 months, and the father has seen the child in the past month at 36 months $(N=2,691)$.

\section{Evaluation of the BSF Intervention}

Mathematica Policy Research conducted a rigorous evaluation of the BSF relationship-strengthening intervention and found no effects on key outcomes, such as couples' relationship quality, coparenting relationship quality, likelihood of marriage, and father involvement (Wood et al., 2012). One exception was a small positive effect of the intervention on child outcomes, with children of parents in the intervention group showing fewer behavior problems compared with children of parents in the control group. Thus, we controlled for the BSF intervention in the analysis by including a covariate for whether the family was in the treatment or control group.

\section{Measures}

Parental relationship status. For the parental relationship status variable, we used mothers' reports of the parents' relationship and residential status at baseline and 15 months. At both waves, mothers indicated whether they are currently married to the father and whether they currently live together in the same household (all, most, some, or none of the time). We constructed a 
measure indicating whether parents were (a) married at 15 months, (b) cohabiting (i.e., residential) all or most of the time at both time points, and (c) churning between living together all/most of the time at baseline and some/ none of the time at 15 months or living together some/none of the time at baseline and all/most of the time at 15 months. In our analyses, we tested for moderation across the married, cohabiting, and churning categories.

Destructive interparental conflict. Destructive interparental conflict (Wood et al., 2010) was assessed at 15 months with nine items that measured mothers' and fathers' perceptions of the level of contempt or criticism they display to each other (e.g., "Little arguments turn into ugly fights with accusations, criticisms, name calling, or bringing up past hurts"), tendency to escalate arguments or withdraw (e.g., "When we argue, one of us withdraws and refuses to talk about it any more"), and other harmful conflict management behaviors (e.g., "When we argue, one of us is going to say something we will regret"). Respondents rated these items on a 4-point scale from $1=$ often to $4=$ never. Items were reverse-coded so that higher scores reflect more frequent use of destructive conflict. We created a composite scale by averaging the nine items (mothers $\alpha=.87$; fathers $\alpha=.87$ ).

Constructive interparental conflict. Constructive interparental conflict (Wood et al., 2010) was assessed at 15 months with five items that measured mothers' and fathers' perceptions of positive relations and cooperation in their relationship. Some items were in reference to a specific person in the relationship (i.e., "[Partner] is good at calming me when I get upset," "I feel respected even when we disagree") while other items were more general to the relationship (i.e., "Even when arguing we can keep a sense of humor," "We are good at solving our differences," "We are pretty good listeners, even when we have different positions on things"). Respondents rated these items on a 4-point scale from $1=$ often to $4=$ never. Items were reverse-coded so that higher scores reflect more frequent use of constructive conflict. We created a composite scale by averaging the five items (mothers $\alpha=.83$; fathers $\alpha=.80)$.

IPV victimization. IPV victimization was measured at 15 months with 12 items from the physical assault subscale (e.g., hitting, slapping, and kicking) and a single item from the sexual coercion subscale (i.e., partner used force or threats to make you have sex or do sexual things you did not want to do) of the revised Conflict Tactics Scale (CTS2; Straus et al., 1996). Respondents indicated whether the act was committed against them in the past year by anyone, including the other parent (or their current partner, if 
applicable) or another partner they were involved with in the past year $(0=$ no, $1=$ yes $)$. In each site except Atlanta, follow-up questions asked who committed the violence (i.e., the other parent, a current partner, and/ or another partner). The institutional review board in Atlanta would not allow questions identifying the perpetrator of the violence. To retain the 421 Atlanta couples in our analytic sample, we used the general report of IPV included in all cities. In the other seven sites, $91.2 \%$ of mothers who reported violence from any partner also reported violence from the BSF father. Similarly, $89.8 \%$ of fathers who reported violence from any partner also reported violence from the BSF mother. Thus, most general reports of violence include perpetration by the other parent. Although a limitation of this study is that some of the reports of IPV are in reference to a partner who is not the original BSF parent, the large majority of cases are in reference to the other parent. We created two dichotomous variables: one for "father IPV victimization" to indicate whether any of these acts had been committed against the father by the mother or another partner and another for "mother IPV victimization" to indicate whether any of these acts have been committed against the mother by the father or another partner $(0=$ no IPV, $1=$ any IPV). This procedure is consistent with the scoring method recommended by Straus and commonly used with the CTS2 physical assault and sexual coercion subscales (Straus, 2004).

Child behavior problems. Our dependent variable was child behavior problems assessed at 36 months with 26 items from the Behavior Problems Index (BPI; Peterson \& Zill, 1986). These items include child internalizing (e.g., "Cries too much," "Worries too much") and externalizing (e.g., "Has a very strong temper and loses it easily," "Cheats or tells lies") behavior problems. Mothers' and fathers' eligibility to answer questions related to child outcomes was determined by how much of the time they each lived with the child or saw the child. Mothers responded to the BPI in $99 \%$ of cases in married and cohabiting families and $98 \%$ of the time in churning families. The father contributed to $6 \%$ of cases in married families, $8 \%$ of cases in cohabiting families, and $15 \%$ of cases in churning families. We used all BPI data available from both parents. Only the mother answered these questions in $90.38 \%$ of cases. In $8.4 \%$ of cases, both parents answered, and responses were averaged. In $1.23 \%$ of cases, only the father answered the BPI. The parent(s) rated these items on a 3-point scale from $1=$ often true to $3=$ never true. Items were reverse-coded so that higher scores reflect higher levels of child behavior problems. Following the procedure from Davies et al. (2012), we created a composite scale by averaging the 26 items $(\alpha=.87)$. 
Child emotional insecurity amid parental conflict. Child emotional insecurity was assessed at 36 months with 10 items drawn from the Security in the Marital Subsystem-Parent Report Inventory (SIMS-PR; Davies et al., 2002). These items include child's reactions to seeing interparental arguments and disagreements during the past month (e.g., "[Child] couldn't seem to calm down after you argued," "[Child] started hitting, kicking, slapping, or throwing things at family members"). Similar to the child behavior problem measure, we used data from each parent eligible to complete these items. In most cases $(91.3 \%)$, only the mother had completed the items, followed by both parents $(6.43 \%)$, and father only $(2.27 \%)$. Parents rated these items on a 4-point scale from $1=$ often to $4=$ never. Items were reverse-coded so that higher scores reflect higher levels of child emotional insecurity in the presence of interparental conflict. We created a composite scale by averaging the 10 items $(\alpha=.85)$.

Control variables. Socioeconomic and demographic characteristics were assessed at baseline including mother's age; father's age; whether both parents reported being Hispanic, White, Black, or another race/ethnicity; whether the parents both had less than a high school education, one of them had a high school diploma, or both had a high school diploma; number of children the mother had with the BSF father prior to the focal child's birth (capped at five); random assignment to the BSF intervention group; and the child's sex. Depressive symptoms were measured at 15 months with the 12 -item version of the Center for Epidemiologic Studies Depression Scale (CES-D; Radloff, 1977). Items assess how respondents felt or behaved in the past week (e.g., "I felt depressed," "I felt sad," "I was bothered by things that usually don't bother me"), rated on a 4-point scale from 1 = rarely or none of the time (i.e., less than 1 day in the past week) to $4=$ most or all of the time (i.e., 5-7 days in the past week) (mothers $\alpha=.86$; fathers $\alpha=.82$ ).

\section{Analytic Strategy}

In relation to the first research question, we conducted path model analysis in Stata 15.0 of the full sample to examine mothers' and fathers' reports of conflict and associations with child emotional insecurity and behavior problems. Interparental conflict behaviors predicted child behavior problems at 36 months, with child emotional insecurity at 36 months as a mediator. The mediation analysis included an assessment of both direct and indirect effects of the independent variables (i.e., mothers' and fathers' self-reports of IPV victimization by their partner and either constructive conflict or destructive conflict) on the dependent variables of child emotional insecurity and child 
behavior problems. Constructive and destructive conflict behaviors were in separate models because they had a moderate inverse correlation, resulting in model instability when including both variables in the same analyses. We used bootstrapping with 500 replications to increase the robustness of the standard errors of the indirect effects. To answer the second research question, we conducted multigroup path model analyses, with three groups: married $(n=600)$, cohabiting $(n=1,373)$, and churning families $(n=718)$. We used unstandardized betas to allow for direct comparison of coefficients between groups. We compared model fit across groups using a chi-square difference test, also known as a likelihood ratio test. The comparative fit index (CFI) and the root mean square error of approximation (RMSEA) were used to evaluate the fit between the model and the data, with values of .95 for CFI and .06 for RMSEA suggesting good fit (Hu \& Bentler, 1999). The highest variance inflation factor (VIF) was 1.93 suggesting no multicollinearity.

The descriptive analysis conducted in this study (reported below, and seen in Table 1) showed that parents in married, cohabiting, and churning families differed significantly in levels of depressive symptoms, constructive conflict, destructive conflict, and IPV victimization, thus providing an empirical justification for examining differences in mechanisms by parental relationship status subgroups. Furthermore, as reported in a previous study (Lee et al., 2019), a confirmatory factor analysis of the interparental conflict items showed that the constructive conflict and destructive conflict items represented distinct but correlated constructs. This supports the inverse correaltion we found between the two constructs in our analyses. This evidence provided justification for modeling constructive and destructive interparental conflict and IPV victimization as separate constructs for each parent, an approach also consistent with prior research (Lee et al., 2019; Warmuth et al., 2020).

We used full information maximum likelihood (FIML or MLMV in Stata) estimation to account for missing data. Seventy eight percent of the sample had complete data on the dependent and predictor variables. The variables with the most missing data were fathers' reports of constructive and destructive conflict (18\%), followed by IPV victimization and depressive symptoms (17\%). Among mothers, constructive and destructive conflict had the most missing data (11\%), followed by depressive symptoms and IPV victimization $(9 \%)$. Child sex was missing in $6 \%$ of cases and parents' race and education were missing in $1 \%$ of cases. The grouping variable (i.e., parental relationship status) was missing in $10 \%$ of cases. A limitation of FIML in multigroup analysis is that FIML is not permitted on the grouping variable. That is, any missing data due to the parental relationship status variable would be automatically dropped. To account for missing data on our grouping variable, we used multiple imputation with chained equations prior to running the path 


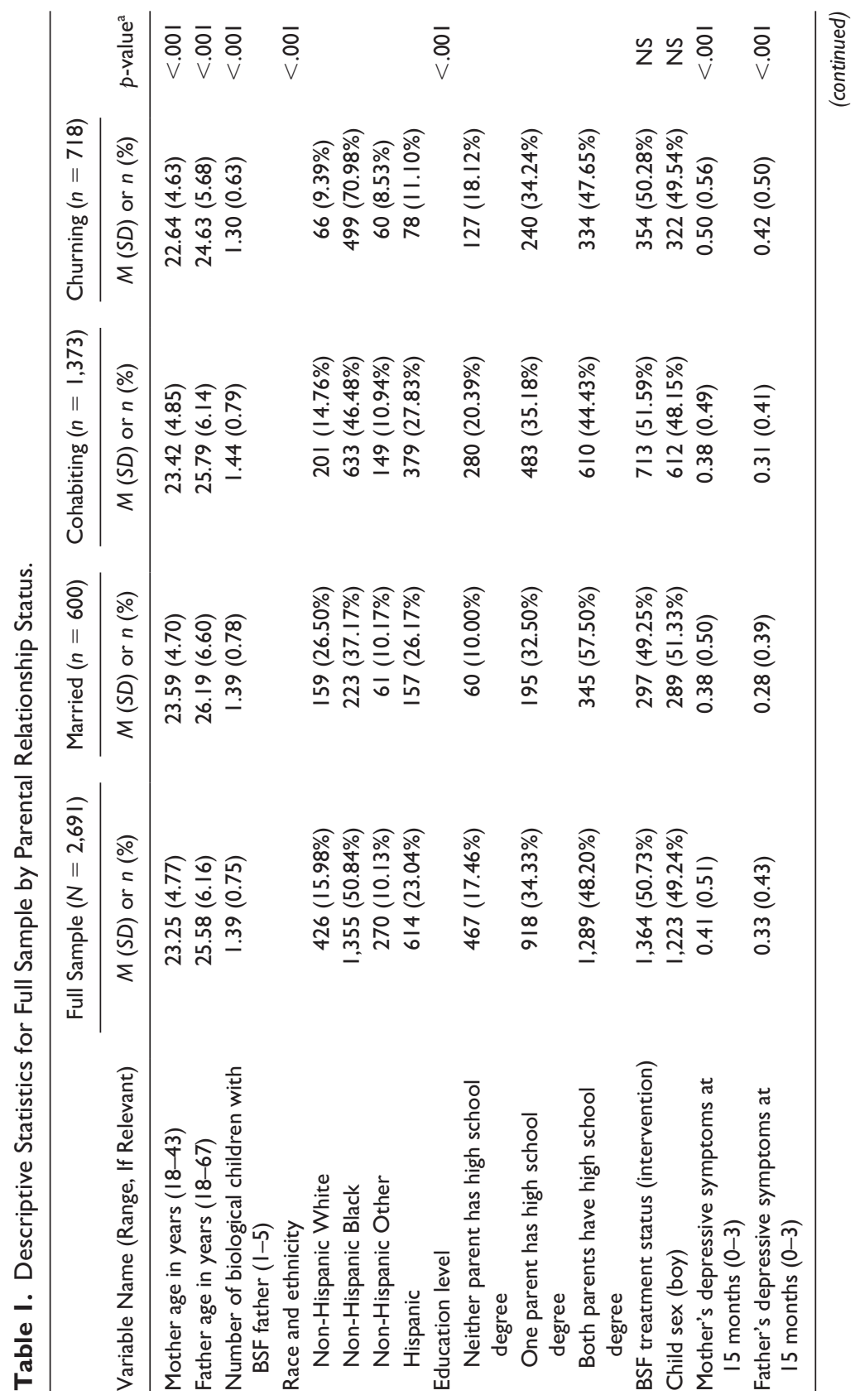




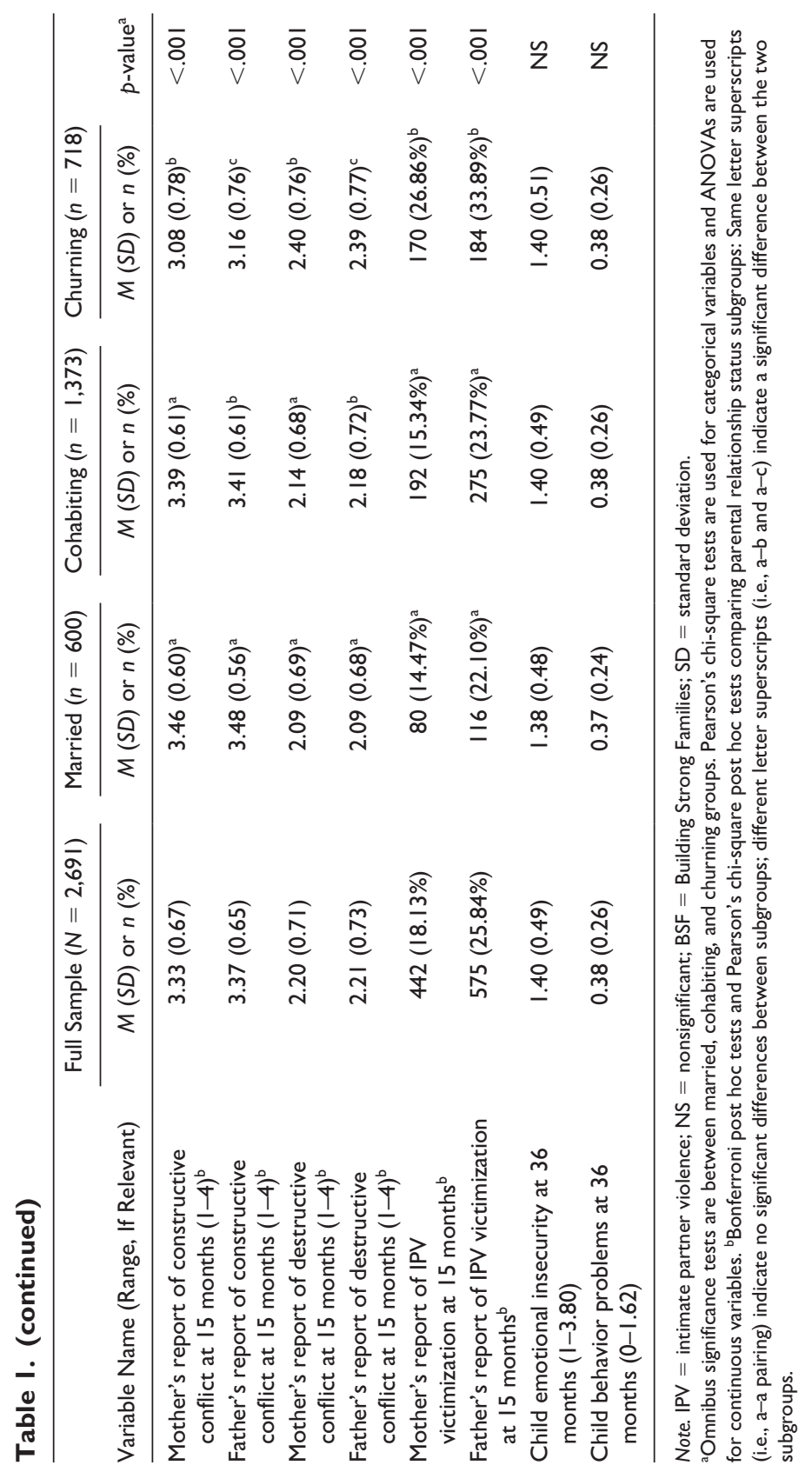


models. The imputation equation included the following variables: whether the parents were married at baseline and, if not, the mothers' reports of the likelihood that they would get married; mother's age; father's age; whether the father was employed at baseline; and parents' race/ethnicity. We generated five imputed data sets and used the imputed data on parental relationship status from the first data set for our analysis. Results were similar across the five data sets. Although there are limitations to this approach, namely that we are unable to account for uncertainty regarding parental relationship status across imputed data sets, this maximizes our sample size and has been used previously in parenting research (e.g., Turney, 2014).

\section{Results}

Descriptive statistics for the full sample and by parental relationship status are shown in Table 1. In general, mothers and fathers reported similar levels of destructive conflict and constructive conflict. IPV victimization in the past year was reported by $18.13 \%$ of mothers and $25.84 \%$ of fathers. A significant Pearson's chi-square test suggested IPV victimization differed across groups. There were statistically significant differences across parental relationship status in variable means except for child behavior problems, child emotional insecurity, child sex, and whether the family was part of the BSF treatment or the control group.

Because the descriptive omnibus tests analyses above do not determine which groups differed from each other, we conducted Bonferroni post hoc tests and Pearson's post hoc tests comparing parental relationship status subgroups to examine which subsets experienced differing levels of conflict. In Table 1, mothers in churning families reported significantly less constructive conflict and significantly more destructive conflict than mothers in married and cohabiting families. Mothers in married and cohabiting families did not differ significantly in their reports of constructive conflict and destructive conflict. Fathers' reports of constructive conflict and destructive conflict differed significantly between subgroup of parental relationship status. Married fathers reported the highest levels of constructive conflict and the lowest levels of destructive conflict, followed by cohabiting fathers. Churning fathers reported the lowest levels of constructive conflict and the highest levels of destructive conflict. Regarding IPV victimization, mothers and fathers in churning families reported significantly higher levels of IPV victimization than mothers and fathers in married and cohabiting families. Mothers and fathers in married and cohabiting families did not differ significantly in their reported IPV victimization. 


\section{Full Path Model Results}

Before testing for moderation by parental relationship status, we present the results for the full sample first. Table 2 shows results for the models including constructive conflict, $\chi^{2}(10)=44.98, p<.001$, RMSEA $=.04,90 \%$ $\mathrm{CI}=[.03, .05], \mathrm{CFI}=.99$, and destructive conflict, $\chi^{2}(10)=45.37$, $p<.001, \mathrm{RMSEA}=.04,90 \% \mathrm{CI}=[.03, .05], \mathrm{CFI}=.99$. Path coefficients for the full sample are in Figures 1 and 2. The full sample results are the first set of coefficients in each of the figures. In Figure 1, for the full sample, motherreported constructive conflict did not have a significant association with child emotional insecurity but had a small negative association with child behavior problems. In Figure 2, for the full sample, mother-reported destructive conflict was a significant predictor of both child emotional insecurity and child behavior problems. Child emotional insecurity mediated the relationship between mother-reported destructive conflict and child behavior problems.

\section{Structural Invariance Tests}

Multigroup models allowed us to test whether there were statistically significant differences in model fit between constrained and unconstrained models. We limited these comparisons to two groups at a time (i.e., married and cohabiting, married and churning, and cohabiting and churning). We ran the model with structural paths constrained to be equal between groups and then ran the model with structural paths unconstrained (i.e., allowed to differ) between groups. In each comparison, the chi-square difference test indicated the constrained model had significantly worse model fit, so we present two unconstrained models (one including constructive conflict and another including destructive conflict) with three groups in each model.

\section{Multigroup Path Model Results}

Figure 1 and Table 3 shows the model including mother- and father-reported constructive conflict and IPV victimization, $\chi^{2}(30)=60.81, p=.001$, RMSEA $=.03,90 \% \mathrm{CI}=[.02, .05], \mathrm{CFI}=.99$. Figure 2 and Table 4 shows the model including destructive conflict and IPV, $\chi^{2}(30)=60.48, p=.001$, RMSEA $=.03,90 \% \mathrm{CI}=[.02, .05], \mathrm{CFI}=.99$. Paths were estimated between (a) mother- and father-reported constructive and destructive conflict and child behavior problems, (b) mother- and father-reported constructive and destructive conflict and child emotional insecurity, and (c) child emotional insecurity and child behavior problems. In the figures, paths in 
Table 2. Full Group Path Model Results for Interparental Constructive Conflict, Destructive Conflict, and IPV.

\begin{tabular}{|c|c|c|c|c|}
\hline \multirow[b]{2}{*}{ Regression Paths } & \multicolumn{2}{|c|}{$\begin{array}{l}\text { Constructive } \\
\text { Conflict and IPV }\end{array}$} & \multicolumn{2}{|c|}{$\begin{array}{c}\text { Destructive } \\
\text { Conflict and IPV }\end{array}$} \\
\hline & $b$ & SE & $b$ & SE \\
\hline \multicolumn{5}{|l|}{ Child behavior problems } \\
\hline Child emotional insecurity & .20 & $.01 * * *$ & .20 & $.01 * * *$ \\
\hline $\begin{array}{l}\text { Mother's report of interparental } \\
\text { conflict }\end{array}$ & -.03 & $.01 * *$ & .05 & $.01 * * *$ \\
\hline $\begin{array}{l}\text { Mother's report of IPV } \\
\text { victimization (Yes) }\end{array}$ & -.01 & .01 & -.02 & $.02 \dagger$ \\
\hline $\begin{array}{l}\text { Father's report of interparental } \\
\text { conflict }\end{array}$ & -.01 & .01 & .00 & .01 \\
\hline $\begin{array}{l}\text { Father's report of IPV } \\
\text { victimization (Yes) }\end{array}$ & .00 & .01 & .00 & .01 \\
\hline \multicolumn{5}{|c|}{ Race and ethnicity (reference: Black) } \\
\hline White & .01 & .01 & .01 & .01 \\
\hline Hispanic & .05 & $.01 * * *$ & .05 & $.01 * * *$ \\
\hline Other & -.01 & .01 & -.01 & .01 \\
\hline Education level & -.02 & $.01 * *$ & -.02 & $.01 * *$ \\
\hline $\begin{array}{l}\text { Number of biological children } \\
\text { with BSF father }\end{array}$ & .00 & .01 & .00 & .01 \\
\hline Mother's depressive symptoms & .05 & $.01 * * *$ & .04 & $.01 * * *$ \\
\hline Father's depressive symptoms & .00 & .01 & .00 & .01 \\
\hline Mother age in years & .00 & .00 & .00 & .00 \\
\hline Father age in years & .00 & .00 & .00 & .00 \\
\hline Child sex (boy) & .02 & $.01 *$ & .02 & $.01 *$ \\
\hline $\begin{array}{l}\text { BSF treatment status } \\
\text { (intervention) }\end{array}$ & -.01 & .01 & -.01 & .01 \\
\hline \multicolumn{5}{|l|}{ Child emotional insecurity } \\
\hline $\begin{array}{l}\text { Mother's report of interparental } \\
\text { conflict }\end{array}$ & .00 & .02 & .12 & $.02 * * *$ \\
\hline $\begin{array}{l}\text { Mother's report of IPV } \\
\text { victimization (Yes) }\end{array}$ & .16 & $.03 * * *$ & .08 & $.03 *$ \\
\hline $\begin{array}{l}\text { Father's report of interparental } \\
\text { conflict }\end{array}$ & .00 & .02 & .01 & .02 \\
\hline $\begin{array}{l}\text { Father's report of IPV } \\
\text { victimization (Yes) }\end{array}$ & .02 & .03 & .00 & .03 \\
\hline \multicolumn{5}{|c|}{ Race and ethnicity (reference: Black) } \\
\hline White & .09 & $.03 * *$ & .09 & $.03 * *$ \\
\hline Hispanic & .03 & .02 & .03 & .02 \\
\hline Other & .04 & .03 & .03 & .03 \\
\hline
\end{tabular}


Table 2. (continued)

\begin{tabular}{|c|c|c|c|c|}
\hline \multirow[b]{2}{*}{ Regression Paths } & \multicolumn{2}{|c|}{$\begin{array}{l}\text { Constructive } \\
\text { Conflict and IPV }\end{array}$} & \multicolumn{2}{|c|}{$\begin{array}{l}\text { Destructive } \\
\text { Conflict and IPV }\end{array}$} \\
\hline & $b$ & SE & $b$ & SE \\
\hline Education level & .00 & .01 & -.01 & .01 \\
\hline $\begin{array}{l}\text { Number of biological children } \\
\text { with BSF father }\end{array}$ & -.03 & $.0 I^{*}$ & -.03 & $.01 *$ \\
\hline Mother's depressive symptoms & .15 & $.02 * * *$ & .10 & $.02 * * *$ \\
\hline Father's depressive symptoms & .04 & .03 & .02 & .03 \\
\hline Mother age in years & .00 & .00 & .00 & .00 \\
\hline Father age in years & .00 & $.00 *$ & .00 & $.00 *$ \\
\hline Child sex (boy) & -.01 & .02 & .00 & .02 \\
\hline $\begin{array}{l}\text { BSF treatment status } \\
\text { (intervention) }\end{array}$ & -.04 & $.02 *$ & -.04 & $.02 *$ \\
\hline$R^{2}$ & .22 & & .22 & \\
\hline
\end{tabular}

Note. $N=2,69 I . b$ is unstandardized coefficients. $S E$ is bootstrapped standard errors. IPV = intimate partner violence.

${ }^{\dagger} p<.10$. ${ }^{*} p<.05$. **p $<.01$. ***p $<.001$.

which any of the three groups had a significant coefficient are shown in bolded lines, and paths that were nonsignificant for all groups are shown in dashed lines.

Constructive conflict, IPV, and child outcomes. Path model results examining the associations between constructive conflict, IPV, child emotional insecurity and child behavior problems showed that mother-reported constructive conflict was not directly associated with child emotional insecurity. However, in married families, father-reported constructive conflict was associated with lowered levels of child emotional insecurity, $b=-.09, p=.035,95 \% \mathrm{CI}=[-.18,-.01]$. Mother-reported constructive conflict was directly associated with a lower level of child behavior problems among cohabiting families only, $b=-.04, p=.002$, $95 \% \mathrm{CI}=[-.07,-.02]$. Mother-reported IPV victimization was associated with higher child emotional insecurity among each family configuration: married, $b=.23, p=.003,95 \% \mathrm{CI}=[.08, .37]$; cohabiting, $b=.19, p<.001,95 \%$ $\mathrm{CI}=[.10, .29]$; and churning: $b=.10, p=.046,95 \% \mathrm{CI}=[.002, .20]$. Maternal IPV victimization, paternal IPV victimization, and father-reported constructive conflict were not directly associated with child behavior problems.

For all three parental relationship subgroups, child emotional insecurity was a significant predictor of child behavior problems: married $b=.19, p<.001$, $95 \% \mathrm{CI}=[.14, .23]$; cohabiting, $b=.21, p<.001,95 \% \mathrm{CI}=[.19, .24]$; and churning, $b=.22, p<.001,95 \% \mathrm{CI}=[.18, .26]$. In addition to these direct 


\section{MONTHS}

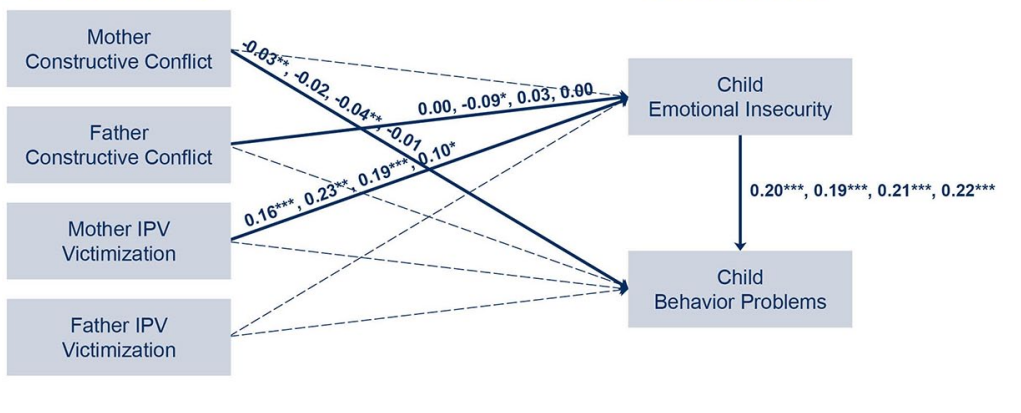

Figure I. Path model examining mothers' and fathers' reports of constructive conflict and intimate partner violence (IPV) victimization from their partner at I5 months as predictors of child emotional insecurity and child behavior problems at 36 months.

Note. The first coefficient is for the full sample (married, cohabiting, and churning couples combined), the second coefficient is for married couples only, the third coefficient is for cohabiting couples only, and the last coefficient is for churning couples only. Parameter estimates are unstandardized path coefficients. Study variables were regressed on a full set of control variables, including mother's age, father's age, number of biological children, couple's ethnicity and race, couple's education level, BSF treatment status, child sex, mothers' depressive symptoms, and fathers' depressive symptoms. Model fit for the multigroup model for married, cohabiting, and churning couples: $\chi^{2}(30)=60.8 \mathrm{I}, p=.00 \mathrm{I}$, RMSEA $=.03, \mathrm{CFI}=$ .99. BSF = Building Strong Families.

$* p<.05$. **p $<.01$. *** $p<.001$.

effects, we tested whether there were indirect effects of conflict on child behavior problems through emotional insecurity. To do so, we produced bootstrapped standard errors of the indirect effects using 500 replications. Among mothers, there were no significant indirect effects of interparental constructive conflict. Regarding maternal IPV victimization, there were significant positive indirect effects among married, $b=.04, p=.003,95 \% \mathrm{CI}=[.01, .07]$; and cohabiting families, $b=.04, p<.001,95 \% \mathrm{CI}=[.02, .06]$. The estimate of the indirect effect for churning families had more uncertainty, $b=.02, p=.051,95 \%$ $\mathrm{CI}=[-.0001, .05]$. For fathers, the only significant indirect effect was among married fathers, in which father-reported constructive conflict had a small negative indirect effect on behavior problems, $b=-.02, p=.044,95 \%$ $\mathrm{CI}=[-.04,-.0005]$.

Destructive conflict, IPV, and child outcomes. Of note in this model, there were no direct or indirect effects of father-reported destructive conflict or IPV victimization on either child emotional insecurity or child behavior 


\section{MONTHS}

\section{MONTHS}

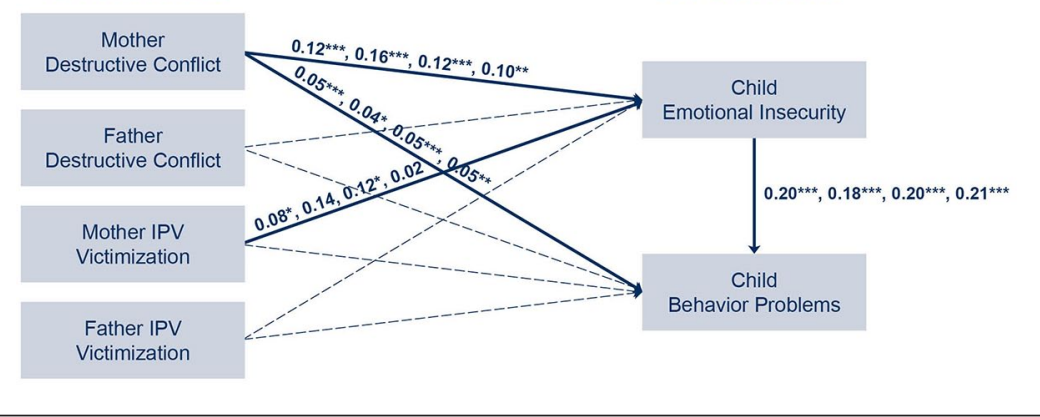

Figure 2. Path model examining mothers' and fathers' reports of destructive conflict and intimate partner violence (IPV) victimization from their partner at I5 months as predictors of child emotional insecurity and child behavior problems at 36 months.

Note. The first coefficient is for the full sample (married, cohabiting and churning couples combined), the second coefficient is for married couples only, the third coefficient is for cohabiting couples only, and the last coefficient is for churning couples only. Parameter estimates are unstandardized path coefficients. Study variables were regressed on a full set of control variables, including mother's age, father's age, number of biological children, couple's ethnicity and race, couple's education level, BSF treatment status, child sex, mother's depressive symptoms, and fathers' depressive symptoms. Model fit for the multigroup model for married, cohabiting, and churning couples: $\chi^{2}(30)=60.48, p=.00 \mathrm{I}$, RMSEA $=.03, \mathrm{CFI}=$ .99. BSF = Building Strong Families.

$* p<.05 . * * p .01$. $* * * p<.001$.

problems. Mother-reported destructive conflict was significantly associated with higher levels of child emotional insecurity for each parental relationship status subgroup: married, $b=.16, p<.001,95 \% \mathrm{CI}=[.08, .23]$; cohabiting, $b=.12, p<.001,95 \% \mathrm{CI}=[.07, .17]$; and churning, $b=.10$, $p=.007,95 \% \mathrm{CI}=[.03, .17]$. Maternal destructive conflict also had small direct effects on child behavior problems for each parental relationship status subgroup: married, $b=.04, p=.021,95 \% \mathrm{CI}=[.01, .07]$; cohabiting, $b=.05, p<.001,95 \% \mathrm{CI}=[.03, .08]$; and churning, $b=.05, p=.008$, $95 \% \mathrm{CI}=[.01, .08]$. Maternal IPV victimization was associated with higher child emotional insecurity among cohabiting families, $b=.12, p=.017$, $95 \% \mathrm{CI}=[.02, .21]$. There was more uncertainty around the association for married families, $b=.14, p=.052,95 \% \mathrm{CI}=[-.001, .28]$. Maternal IPV victimization was not directly associated with child behavior problems.

Similar to the constructive conflict model, we examined whether destructive conflict behaviors had any indirect effects on child behavior problems via child emotional insecurity. Mother-reported destructive 
Table 3. Multigroup Path Model Results for Constructive Interparental Conflict and IPV.

\begin{tabular}{|c|c|c|c|c|c|c|}
\hline \multirow[b]{2}{*}{ Regression Paths } & \multicolumn{2}{|c|}{ Married } & \multicolumn{2}{|c|}{ Cohabiting } & \multicolumn{2}{|c|}{ Churning } \\
\hline & $b$ & SE & $b$ & SE & $b$ & SE \\
\hline \multicolumn{7}{|l|}{ Child behavior problems } \\
\hline Child emotional insecurity & .19 & $.02 * * *$ & .21 & $.01 * * *$ & .22 & $.02 * * *$ \\
\hline Mother's report of constructive conflict & -.02 & .02 & -.04 & $.01 * *$ & -.01 & .01 \\
\hline Mother's report of IPV victimization (Yes) & -.02 & .03 & -.02 & .02 & .01 & .02 \\
\hline Father's report of constructive conflict & -.04 & $.02 \dagger$ & -.01 & .01 & .02 & .02 \\
\hline Father's report of IPV victimization (Yes) & -.02 & .03 & .00 & .02 & .01 & .02 \\
\hline \multicolumn{7}{|l|}{ Race and ethnicity (reference: Black) } \\
\hline White & .02 & .02 & .02 & .02 & .00 & .03 \\
\hline Hispanic & .06 & $.03^{*}$ & .07 & $.02 * * *$ & -.02 & .03 \\
\hline Other & .00 & .03 & .03 & .02 & -.07 & $.03 *$ \\
\hline Education level & -.02 & .01 & -.02 & $.01 * *$ & -.01 & .01 \\
\hline Number of biological children with BSF father & -.01 & .01 & -.01 & .01 & .04 & $.02 *$ \\
\hline Mother's depressive symptoms & .03 & .02 & .06 & $.02 * * *$ & .05 & $.02 *$ \\
\hline Father's depressive symptoms & -.01 & .03 & .01 & .02 & .00 & .02 \\
\hline Mother age in years & .00 & .00 & .00 & .00 & .00 & $.00 \dagger$ \\
\hline Father age in years & .00 & .00 & .00 & .00 & .00 & .00 \\
\hline Child sex (boy) & .05 & $.02 *$ & .02 & .01 & .01 & .02 \\
\hline BSF treatment status (intervention) & .00 & .02 & -.01 & .01 & -.01 & .02 \\
\hline \multicolumn{7}{|l|}{ Child emotional insecurity } \\
\hline Mother's report of constructive conflict & -.03 & .05 & .00 & .02 & .03 & .03 \\
\hline Mother's report of IPV victimization (Yes) & .23 & $.08^{* *}$ & .19 & $.05 * * *$ & .10 & $.05 *$ \\
\hline Father's report of constructive conflict & -.09 & $.04 *$ & .03 & .02 & .00 & .03 \\
\hline Father's report of IPV victimization (Yes) & .03 & .06 & .06 & .04 & -.05 & .05 \\
\hline \multicolumn{7}{|l|}{ Race and ethnicity (reference: Black) } \\
\hline White & .18 & $.05^{* * * *}$ & .06 & .04 & .02 & .07 \\
\hline Hispanic & .09 & $.05 \dagger$ & -.01 & .03 & .08 & .06 \\
\hline Other & .08 & .07 & .03 & .04 & .02 & .07 \\
\hline Education level & .00 & .03 & -.03 & $.02 \dagger$ & .06 & $.03 *$ \\
\hline Number of biological children with BSF father & -.03 & .03 & -.01 & .02 & -.07 & $.03 *$ \\
\hline Mother's depressive symptoms & .14 & $.05^{* *}$ & .18 & $.03 * * *$ & .13 & $.04 * *$ \\
\hline Father's depressive symptoms & .05 & .06 & .02 & .04 & .06 & .05 \\
\hline Mother age in years & .00 & .00 & .01 & .00 & .00 & .01 \\
\hline Father age in years & .00 & .00 & .00 & $.00 \dagger$ & .00 & .00 \\
\hline Child sex (boy) & .03 & .04 & -.04 & .03 & .00 & .04 \\
\hline BSF treatment status (intervention) & -.05 & .04 & -.05 & $.03 \dagger$ & -.01 & .04 \\
\hline$N$ & 600 & & I,373 & & 718 & \\
\hline$R^{2}$ & .20 & & .20 & & .14 & \\
\hline
\end{tabular}

Note. $b$ is unstandardized coefficients. SE is bootstrapped standard errors. IPV = intimate partner violence. $t_{p}<.10 . * p<.05 . * * p<.01 . * * * p<.001$.

conflict had a significant indirect effect among each family configuration: married, $b=.03, p<.001,95 \% \mathrm{CI}=[.01, .04$; cohabiting, $b=.02$, $p<.001,95 \% \mathrm{CI}=[.01, .03]$; and churning, $b=.02, p=.009,95 \%$ 
Table 4. Multigroup Path Model Results for Destructive Interparental Conflict and IPV.

\begin{tabular}{|c|c|c|c|c|c|c|}
\hline \multirow[b]{2}{*}{ Regression Paths } & \multicolumn{2}{|c|}{ Married } & \multicolumn{2}{|c|}{ Cohabiting } & \multicolumn{2}{|c|}{ Churning } \\
\hline & $b$ & SE & $b$ & SE & $b$ & SE \\
\hline \multicolumn{7}{|l|}{ Child behavior problems } \\
\hline Child emotional insecurity & .18 & $.02 * * *$ & .20 & $.01 * * *$ & .21 & $.02 * * *$ \\
\hline Mother's report of destructive conflict & .04 & $.02 *$ & .05 & $.01 * * *$ & .05 & $.02^{* *}$ \\
\hline Mother's report of IPV victimization (Yes) & -.04 & .03 & -.02 & .02 & -.01 & .03 \\
\hline Father's report of destructive conflict & .01 & .02 & -.01 & .01 & .00 & .02 \\
\hline Father's report of IPV (Yes) & -.02 & .03 & .01 & .02 & -.01 & .03 \\
\hline \multicolumn{7}{|l|}{ Race and ethnicity (reference: Black) } \\
\hline White & .02 & .02 & .02 & .02 & -.01 & .03 \\
\hline Hispanic & .06 & $.02 *$ & .07 & $.02 * * *$ & -.02 & .03 \\
\hline Other & .00 & .03 & .03 & .02 & -.07 & $.03 *$ \\
\hline Education level & -.02 & .01 & -.03 & $.01 * *$ & -.01 & .01 \\
\hline Number of biological children with BSF father & -.01 & .01 & -.01 & .01 & .04 & .02 \\
\hline Mother's depressive symptoms & .02 & .02 & .06 & .02 & .03 & .02 \\
\hline Father's depressive symptoms & -.01 & .03 & .02 & .02 & -.01 & .02 \\
\hline Mother's age & .00 & .00 & .00 & .00 & .00 & $.00 \dagger$ \\
\hline Father's age & .00 & .00 & .00 & .00 & .00 & .00 \\
\hline Child sex (boy) & .05 & $.02 * *$ & .02 & .01 & .01 & .02 \\
\hline BSF treatment status (intervention) & .00 & .02 & -.01 & .01 & -.01 & .02 \\
\hline \multicolumn{7}{|l|}{ Child emotional insecurity } \\
\hline Mother's report of destructive conflict & .16 & $.04 * * *$ & .12 & $.03^{* * * *}$ & .10 & $.04 * *$ \\
\hline Mother's report of IPV victimization (Yes) & .14 & $.07 \dagger$ & .12 & $.05 *$ & .02 & .06 \\
\hline Father's report of destructive conflict & .03 & .04 & -.02 & .02 & .06 & .04 \\
\hline Father's report of IPV (Yes) & .03 & .06 & .05 & .04 & -.10 & $.05 \dagger$ \\
\hline \multicolumn{7}{|l|}{ Race and ethnicity (reference: Black) } \\
\hline White & .17 & .05 & .07 & $.04 \dagger$ & -.02 & .07 \\
\hline Hispanic & .08 & .04 & -.01 & .03 & .05 & .05 \\
\hline Other & .08 & .07 & .03 & .04 & -.01 & .07 \\
\hline Education level & -.01 & .03 & -.03 & $.02 \dagger$ & .05 & $.03 \dagger$ \\
\hline Number of biological children with BSF father & -.03 & .02 & -.01 & .02 & -.07 & $.03 *$ \\
\hline Mother's depressive symptoms & .06 & .05 & .14 & .03 & .07 & .04 \\
\hline Father's depressive symptoms & .06 & .07 & .02 & .04 & .01 & .05 \\
\hline Mother age in years & .00 & .00 & .00 & .00 & .00 & .01 \\
\hline Father age in years & .00 & .00 & -.01 & $.00 *$ & -.01 & .00 \\
\hline Child sex (boy) & .03 & .04 & -.04 & .03 & .01 & .04 \\
\hline BSF treatment status (intervention) & -.05 & .04 & -.05 & $.03 \dagger$ & -.01 & .04 \\
\hline$N$ & 600 & & 1,373 & & 718 & \\
\hline$R^{2}$ & .20 & & .20 & & .14 & \\
\hline
\end{tabular}

Note. $b$ is unstandardized coefficients. SE is bootstrapped standard errors. IPV = intimate partner violence. $t_{p}<.10 . *_{p}<.05 . *_{p}<.01 . * * * p<.001$.

$\mathrm{CI}=[.01, .04]$. Regarding maternal IPV victimization, only cohabiting families had a significant positive indirect effect, $b=.02, p=.017,95 \%$ $\mathrm{CI}=[.004, .04]$, while there was more uncertainty for indirect effects in 
married families, $b=.03, p=.059,95 \% \mathrm{CI}=[-.001, .05]$. For fathers, there were no significant indirect effects of their perceptions of interparental conflict or their reports of IPV victimization on child outcomes.

\section{Discussion}

There are several key findings from this study. First, overall, mothers' perceptions of destructive and constructive conflict demonstrated a more robust association with child's emotional insecurity and behavior problems compared with fathers' perceptions of destructive and constructive conflict. Only married fathers' perceptions of constructive conflict behaviors showed a direct negative association with child emotional insecurity, as well as a indirect negative association with child behavior problems via emotional insecurity, albeit the indirect effect was small. Fathers' influence was most clearly evident through mothers' reports of IPV victimization, which was associated with child behavior problems across parental relationship status subgroups. Fathers' influence was also evident (but less clearly) in how their behaviors were captured in mothers' reports of destructive conflict, which was associated with child emotional insecurity and child behavior problems.

Second, the outcomes of mother-reported interparental conflict were most pronounced when looking at destructive conflict. That is, across the full sample and all of the parental relationship status groups, mothers' reports of destructive conflict behaviors were associated with higher levels of child emotional insecurity and child behavior problems. For constructive conflict, the results were mixed for married and cohabiting families, with no effects of either mother- or father-reported constructive conflict seen among churning families.

Third, the results of this study supported the tenets of EST. In this large sample of socioeconomically disadvantaged families with young children, child emotional insecurity mediated the association of maternal destructive conflict to child behavior problems.

\section{Constructive and Destructive Conflict Approaches}

The levels of constructive conflict found in this study were high, consistent with other studies of BSF families (Kopystynska et al., 2017, 2020). Yet, in the path models, there were few effects of constructive conflict on child outcomes, with father-reported constructive conflict being the only significant association with child emotional insecurity for married families and mother-reported constructive conflict being associated with child behavior problems in the full sample and among cohabiting families only. Instead, 
destructive conflict had the most robust and consistent associations with child emotional insecurity and child behavior problems across the different family configurations.

These findings can be interpreted within the EST framework. For example, Davies and colleagues (2012) suggested that child emotional insecurity was a central explanatory mechanism for understanding how destructive conflict, but not constructive conflict, is associated with child behavior problems. The authors suggested that "destructive conflict cumulatively supersedes the impact of constructive conflict on children's security processes" (Davies et al., 2012, p. 952). Our results provide additional empirical evidence to support this argument and suggest that constructive conflict is unlikely to counteract or mitigate the effects of destructive conflict or IPV.

\section{Differing Influence of Mothers and Fathers}

Furthermore, these patterns of associations were mainly evident for mothers' reports of destructive conflict. In fact, there were no significant direct or indirect associations of father-reported destructive conflict behaviors with child emotional insecurity or child behavior problems. Fathers' influence was most directly seen through mothers' reports of IPV victimization (discussed further below). The research on fathers' interparental conflict behaviors and child outcomes is mixed. Prior studies have examined the effects of interparental conflict in samples of older children, for example, showing that fathers' marital conflict predicted conduct problems among 4- to 7-year-old children (Webster-Stratton \& Hammond, 1999). Fathers' relationship conflict behaviors predicted internalizing behavior problems among 5- to 8-year-old children (Katz \& Gottman, 1993), and fathers' reports of destructive conflict behaviors were linked with increased aggression among 8- to 16-year-old children (Cummings et al., 2004). El-Sheikh and colleagues (2008) found similar patterns of mothers' and fathers' conflict behaviors on child emotional insecurity and child behavior problems of second and third grade children. However, consistent with the results of the current study, research has found that fathers' positive parenting, negative parenting, and inconsistent parenting were not directly linked to children's emotional insecurity (called "fear of love withdrawal" in that study) (Lux \& Walper, 2019). The authors of this study attributed these results to the "stronger association between parenting and children's emotional insecurity in the mother-child dyad compared to the father-child dyad" (Lux \& Walper, 2019, p. 12).

In addition, some prior studies consisted of participants who were less racially and socioeconomically diverse, with more stable parental relationships. The age of children in most of these earlier studies were older. BSF is 
a large, racially and geographically diverse sample of couples with young children. Thus, differing sociodemographic factors, differing measures of interparental conflict, as well as the age of the children may explain why our results diverged from some prior studies.

Furthermore, our study simultaneously accounted for maternal and paternal perceptions of conflict, whereas other studies have often examined fathers and mothers in separate models. Although the research base is still limited, particularly for studies that examine mothers' and fathers' parenting behaviors simultaneously or dyadically, studies that use diverse samples such as BSF or FFCWS have shown that fathers' parenting behaviors or mental health problems did not have robust associations with the outcome of child behavior problems (e.g., Lee et al., 2015, 2018; Meadows et al., 2007; Ward \& Lee, 2020). The varied results across studies suggest that there is still much need to better understand the influence of fathers' constructive and destructive conflict and parenting behaviors, particularly among socioeconomically disadvantaged families. It is also important to examine a wider range of behaviors toward children, such as harsh punishment (Kim et al., 2014; Lee et al., 2011), and how those behaviors may relate to child emotional insecurity.

It is also possible that fathers' influences in the family system may be weaker after accounting for maternal influences. Findings regarding the relative influence of mothers' and fathers' perceptions of interparental conflict behaviors may be explained in part by the larger role that mothers play in caring for young children. While our sample consisted of father-involved families, in that fathers were married, cohabiting, or in on-again and offagain relationships with the child's mother, it may be that because mothers spend more time with young children compared to fathers (Jones \& Mosher, 2013), mothers' perceptions of interparental conflict and experiences of IPV victimization play a more salient role predicting child behavior problems (Ward \& Lee, 2020). Another possible explanation may be related to evidence showing that physical injuries resulting from IPV tend to be more severe for women than men (Archer, 2000), perhaps in part because men use more severe forms of IPV (e.g., beat, choke, strangle) compared with women (Archer, 2002). It may be that mothers' victimization by their BSF male partners was a consistent predictor of the child outcomes of this study due to the severity of the IPV these mothers endured.

\section{Interparental Conflict Behaviors and Parental Relationship Status}

Broadly consistent with the research of Halpern-Meekin and colleagues, churning mothers and fathers in this study were more depressed and had higher levels of IPV than did married and cohabiting families 
(Halpern-Meekin et al., 2013; Halpern-Meekin \& Turney, 2018). We find that compared with married and cohabiting parents, churning couples reported significantly higher levels of more moderate forms of destructive conflict and significantly lower levels of constructive conflict behaviors, which include behaviors such as listening and maintaining humor during disagreements. This study provides a nuanced picture of interparental conflict among churning couples, who seem to have higher levels of severe and moderate conflict, as well as fewer constructive conflict behaviors that may help to buffer the detrimental consequences of interparental conflict (Davies et al., 2012).

However, even though churning families had higher mean levels of conflict, the path model results did not demonstrate dramatic differences in how interparental conflict related to child behavior problems. Again consistent with EST, the processes by which destructive conflict behaviors influence child emotional insecurity and child behavior problems were similar across parental relationship subgroups, with mother-reported destructive conflict linked to higher levels of child emotional insecurity and child behavior problems, and child emotional insecurity mediating the effects of mother-reported destructive conflict on child behavior problems.

On the whole, constructive conflict behaviors had small and varied effects on child behavior problems, and only among married and cohabiting parents. It is possible that the more conflictual nature of the parental relationship for churning families (Halpern-Meekin et al., 2013; Halpern-Meekin \& Turney, 2016) means these behaviors are not impactful overall on child behavior problems. Put another way, married and cohabiting parents may have a more positive relationship overall, leaving more room to use constructive conflict strategies to solve problems.

\section{IPV in the Context of Constructive and Destructive Interparental Conflict}

IPV was common, with $18 \%$ of mothers and $25 \%$ of fathers reporting at least one form of physical assault or sexual coercion in the past year. Our study did not include psychological or emotional abuse, in which case these numbers likely would have been higher. Even so, the study results were consistent with dozens of prior studies showing that mothers' reports of IPV victimization were significantly associated with poorer child well-being (Cummings \& Davies, 2010; Evans et al., 2008). Relatively few studies have examined both mothers' and fathers' IPV victimization. In this study, fathers reported more IPV victimization than did mothers. However, only mothers' IPV victimization was associated with child outcomes. 


\section{Study Limitations}

We relied on parents' reports of interparental conflict and child outcomes. Thus, self-report biases may influence the study results. The wording of the interparental conflict questions make it difficult to disentangle individual conflict management behaviors. Thus, these measures are primarily indicative of each parents' perception of the level of conflict in their relationship. Most child behavior items were based on mothers' reports. Therefore, fathers' perceptions of child behavior problems are not well represented in this study. The items in this study do not capture all aspects of child emotional insecurity. The items in these analyses do not capture the child's internal representations, which is another element of child emotional insecurity as noted in EST (Davies $\&$ Martin, 2013). The IPV victimization variable was a measure of victimization from any partner. Thus, it may not always be in reference to the other parent. Furthermore, it excludes psychological and emotional abuse, which are well established components of IPV. As such, the estimates of the rates of IPV in the BSF sample may be lower than would be the case if items assessing emotional and psychological IPV had been included in the study. That said, an important strength is having both mothers' and fathers' reports of conflict.

The components of the model examining mediation are cross-sectional because child emotional insecurity and child behavior problems were measured only once at the 36-month follow-up. Mediation analysis can yield biased results when using cross-sectional data (Maxwell \& Cole, 2007).

BSF consisted of socioeconomically disadvantaged parents, most of whom were not married at the time of their child's birth. All BSF couples were initially willing to participate in a relationship skills intervention program. Thus, the results are not generalizable to all parents with a young child. This limitation is also a strength in some respects. BSF is a racially and ethnically diverse sample of parents who experienced socioeconomic disadvantage and relationship instability. Thus, this study contributes important knowledge to understanding family dynamics among of subgroup of families that is highly relevant to healthy marriage and family relationship scholars.

\section{Conclusion and Implications}

This study contributes to knowledge regarding complex family dynamics related to how children may be influenced by interparental conflict in the context of high levels of socioeconomic adversity and as a function of parental relationship status. Although this study found few direct effects of fathers' perceived interparental conflict behaviors on child behavior problems, the results supported the notion that fathers play an influential role 
in the family system via maternal reports of IPV victimization. The study results suggest two primary targets for intervention. First, consistent with decades of family violence research, it is necessary to reduce maternal IPV victimization, which showed negative associations with child behavior problems across family configurations. Second, it is important to reduce destructive conflict behaviors. Mothers' perceptions of these conflict behaviors may be especially salient for child behavior problems. Increasing constructive conflict behaviors may be beneficial, but targeting these behaviors without reducing destructive conflict and IPV does not seem likely to mitigate the effects of interparental conflict on child behavior problems.

\section{Authors' Note}

This study was approved as secondary data analysis by the Institutional Review Board at the University of Michigan - project name: Building Strong Families (HUM00084971).

\section{Acknowledgments}

The authors gratefully acknowledge use of the services and facilities of the Population Studies Center at the University of Michigan. The content is solely the responsibility of the authors and does not necessarily represent the official views of the National Institutes of Health.

\section{Declaration of Conflicting Interests}

The author(s) declared no potential conflicts of interest with respect to the research, authorship, and/or publication of this article.

\section{Funding}

The author(s) disclosed receipt of the following financial support for the research, authorship, and/or publication of this article: This research was supported by a grant from the Eunice Kennedy Shriver National Institute of Child Health and Human Development (NICHD) (grant no. R15HD091763-01) to Dr. Inna Altschul and Dr. Shawna J. Lee. Garrett T. Pace was supported by NICHD (grant no. T32HD007339) and gratefully acknowledges use of services and facilities of the Population Studies Center at the University of Michigan, funded by NICHD grant no. P2CHD041028. Joyce Y. Lee was supported by a graduate fellowship from the Administration for Children and Families Children's Bureau (grant no. 90PR0009-01-00).

\section{ORCID iDs}

Shawna J. Lee (iD https://orcid.org/0000-0003-0562-2856

Joyce Y. Lee (iD https://orcid.org/0000-0003-2805-9277 


\section{References}

Archer, J. (2000). Differences in aggression between heterosexual partners: A metaanalytic review. Psychological Bulletin, 126, 651-680. https://doi.org/10.1037/ 0033-2909.126.5.651

Archer, J. (2002). Sex differences in physically aggressive acts between heterosexual partners: A meta-analytic review. Aggression and Violent Behavior, 7, 313-351. https://doi.org/10.1016/S1359-1789(01)00061-1

Brock, R. L., \& Kochanska, G. (2016). Interparental conflict, children's security with parents, and long-term risk of internalizing problems: A longitudinal study from ages 2 to 10. Development and Psychopathology, 28(1), 45-54. https://doi. org/10.1017/S0954579415000279

Carlson, M. J., McLanahan, S. S., \& Brooks-Gunn, J. (2008). Coparenting and nonresident fathers' involvement with young children after a nonmarital birth. Demography, 45(2), 461-488. https://doi.org/10.1353/dem.0.0007

Charles, P., \& Perreira, K. M. (2007). Intimate partner violence during pregnancy and 1-year post-partum. Journal of Family Violence, 22(7), 609-619. https://doi. org/10.1007/s10896-007-9112-0

Cheung, R. Y., Cummings, E. M., Zhang, Z., \& Davies, P. T. (2016). Trivariate modeling of interparental conflict and adolescent emotional security: An examination of mother-father-child dynamics. Journal of Youth and Adolescence, 45(11), 2336-2352. https://doi.org/10.1007/s10964-015-0406-x

Cummings, E. M., \& Davies, P. T. (1996). Emotional security as a regulatory process in normal development and the development of psychopathology. Development and Psychopathology, 8, 123-139. https://doi.org/10.1017/S0954579400007008

Cummings, E. M., \& Davies, P. T. (2010). Marital conflict and children: An emotional security perspective. Guilford Press.

Cummings, E. M., Goeke-Morey, M. C., \& Papp, L. M. (2003). Children's responses to everyday marital conflict tactics in the home. Child Development, 74, 1918 1929. https://doi.org/10.1046/j.1467-8624.2003.00646.x

Cummings, E. M., Goeke-Morey, M. C., \& Papp, L. M. (2004). Everyday marital conflict and child aggression. Journal of Abnormal Child Psychology, 32, 191202. https://doi.org/10.1023/b:jacp.0000019770.13216.be

Davies, P. T., Forman, E. M., Rasi, J. A., \& Stevens, K. I. (2002). Assessing children's emotional security in the interparental relationship: The security in the interparental subsystem scales. Child Development, 73, 544-562. https://doi. org/10.1111/1467-8624.00423

Davies, P. T., \& Martin, M. (2013). The reformulation of Emotional Security Theory: The role of children's social defense in developmental psychopathology. Developmental Psychopathology, 25(402), 1435-1454. https://doi.org/10.1017/ S0954579413000709

Davies, P. T., Martin, M. J., \& Cicchetti, D. (2012). Delineating the sequelae of destructive and constructive interparental conflict for children with an evolutionary framework. Developmental Psychology, 48(4), 939-955. https://doi. org/10.1037/a0025899 
Davies, P. T., \& Sturge-Apple, M. L. (2007). Advances in the formulation of emotional security theory: An ethologically based perspective. In R. V. Kail (Ed.), Advances in child development and behavior: Vol. 35. Advances in child development and behavior (pp. 87-137). Elsevier Academic Press.

DuRocher Schudlich, T. D., Jessica, N. W., Erwin, S. E. A., \& Rishor, A. (2019). Infants' emotional security: The confluence of parental depression, Interparental conflict, and parenting. Journal of Applied Developmental Psychology, 63, 42-53. https://doi.org/10.1016/j.appdev.2019.05.006

El-Sheikh, M., Cummings, E. M., Kouros, C. D., Elmore-Staton, L., \& Buckhalt, J. (2008). Marital psychological and physical aggression and children's mental and physical health: Direct, mediated, and moderated effects. Journal of Consulting and Clinical Psychology, 76(1), 138-148. https://doi.org/10.1037/0022-006X.76.1.138

Evans, S. E., Davies, C., \& DiLillo, D. (2008). Exposure to domestic violence: A metaanalysis of child and adolescent outcomes. Aggression and Violent Behavior, 13, 131-140. https://doi.org/10.1016/j.avb.2008.02.005

Halpern-Meekin, S., Manning, W., Giordano, P., \& Longmore, M. (2013). Relationship churning, physical violence, and verbal abuse in young adult relationships. Journal of Marriage and Family, 75, 1-12. https://doi.org/10.1111/ j.1741-3737.2012.01029.x

Halpern-Meekin, S., \& Turney, K. (2016). Relationship churning and parenting stress among mothers and fathers. Journal of Marriage and Family, 78(3), 715-729. https://doi.org/10.1111/jomf.12297

Halpern-Meekin, S., \& Turney, K. (2018). Relationship churning and desistance from intimate abuse. Journal of Interpersonal Violence. Advance online publication. https://doi.org/10.1177/0886260518807214

Harding, H. G., Morelen, D., Thomassin, K., Bradbury, L., \& Shaffer, A. (2013). Exposure to maternal-and paternal-perpetrated intimate partner violence, emotion regulation, and child outcomes. Journal of Family Violence, 28(1), 63-72. https://doi.org/10.1007/s10896-012-9487-4

Hu, L., \& Bentler, P. M. (1999). Cutoff criteria for fit indexes in covariance structure analysis: Conventional criteria versus new alternatives. Structural Equation Modeling: A Multidisciplinary Journal, 6(1), 1-55. https://doi.org/10.1080/ 10705519909540118

Jones, J., \& Mosher, W. D. (2013). Fathers' involvement with their children: United States, 2006-2010. National Health Statistics Reports, 71, 1-21.

Katz, L. F., \& Gottman, J. M. (1993). Patterns of marital conflict predict children's internalizing and externalizing behaviors. Developmental Psychology, 29(6), 940-950. https://doi.org/10.1037/0012-1649.29.6.940

Kim, J., Lee, S. J., Taylor, C. A., \& Guterman, N. B. (2014). Dyadic profiles of parental disciplinary behavior and links with parenting context. Child Maltreatment, 19, 79-91. https://doi.org/10.1177/1077559514532009

Kopystynska, O., Barnett, M. A., \& Curran, M. A. (2020). Constructive and destructive interparental conflict, parenting, and coparenting alliance. Journal of Family Psychology, 34, 414-424. https://doi.org/10.1037/fam0000606 
Kopystynska, O., \& Beck, C. J. (2017). Considering destructive interparental conflict and intimate partner abuse: Is there a difference? Family Court Review, 56(2), 209-218.

Kopystynska, O., Paschall, K. W., Barnett, M. A., \& Curran, M. A. (2017). Patterns of interparental conflict, parenting, and child emotional insecurity: A personcentered approach. Journal of Family Psychology, 31(7), 922-932. https://doi. org/10.1037/fam0000343

Lamb, M. E., Pleck, J. H., Charnov, E. L., \& Levine, J. A. (1985). A biosocial perspective on paternal behavior and involvement. In J. B. Lancaster, L. R. Sherrod, A. Rossi, \& J. Altmann (Eds.), Parenting across the life span: Biosocial dimensions (pp. 111-142). Transaction.

Lee, J. Y., Pace, G. T., Lee, S. J., \& Altschul, I. (2019). The associations of constructive and destructive interparental conflict to child wellbeing among low-income families. Journal of Interpersonal Violence. Advance online publication. https:// doi.org/10.1177/0886260519835872

Lee, S. J., Altshul, I., \& Gershoff, E. T. (2015). Wait until your father gets home? Mothers' and fathers' spanking and development of child aggression. Children \& Youth Services Review, 52, 158-166. https://doi.org/10.1016/j.childyouth.2014.11.006

Lee, S. J., Kim, J., Taylor, C. A., \& Perron, B. E. (2011). Profiles of disciplinary behaviors among biological fathers. Child Maltreatment, 16(1), 51-62. https:// doi.org/10.1177/1077559510385841

Lee, S. J., Pace, G. T., Lee, J. Y., \& Knauer, H. (2018). The association of fathers' parental warmth and parenting stress to child behavior outcomes. Children \& Youth Services Review, 91, 1-10. https://doi.org/10.1016/j.childyouth.2018.05.020

Lux, U., \& Walper, S. (2019). A systemic perspective on children's emotional insecurity in relation to father: Links to parenting, interparental conflict and children's social well-being. Attachment \& Human Development, 21, 467-484. https://doi. org/10.1080/14616734.2019.1582597

Martin, J. A., Hamilton, B. E., Osterman, M. J. K., Driscoll, A. K., \& Drake, P. A. (2018). Births: Final data for 2017. National Vital Statistics Reports, 67(8), $1-49$.

Masho, S. W., Rozario, S. S., \& Ferrance, J. L. (2019). Intimate partner violence around the time of pregnancy and utilization of WIC services. Maternal and Child Health Journal, 23(12), 1648-1657. https://doi.org/10.1007/s10995019-02811-7

Maxwell, S. E., \& Cole, D. A. (2007). Bias in cross-sectional analyses of longitudinal mediation. Psychological Methods, 12(1), 23-44.

McCoy, K., Cummings, E. M., \& Davies, P. T. (2009). Constructive and destructive marital conflict, emotional security and children's prosocial behavior. Journal of Child Psychology and Psychiatry, 50(3), 270-279. https://doi.org/10.1111/ j.1469-7610.2008.01945.x

McCoy, K. P., George, M. R. W., Cummings, E. M., \& Davies, P. T. (2013). Constructive and destructive marital conflict, parenting, and children's school and social adjustment. Social Development, 22(4), 651-662. https://doi.org/10.1111/sode.12015 
Meadows, S. O., McLanahan, S. S., \& Brooks-Gunn, J. (2007). Parental depression and anxiety and early childhood behavior problems across family types. Journal of Marriage and Family, 69, 1162-1177. https://doi.org/10.1111/j.17413737.2007.00439.x

Moore, Q., Wood, R. G., Clarkwest, A., Killewald, A., \& Monahan, S. (2012). The long-term effects of Building Strong Families: A relationship skills education program for unmarried parents [Technical supplement]. Mathematica Policy Research.

Peterson, J. L., \& Zill, N. (1986). Marital disruption, parent-child relationships, and behavior problems in children. Journal of Marriage and the Family, 48, 295307. https://doi.org/10.2307/352397

Pleck, J. H. (2010). Paternal involvement: Revised conceptualization and theoretical linkages with child outcomes. In M. E. Lamb (Ed.), The role of the father in child development (pp. 58-93). John Wiley.

Radloff, L. S. (1977). The CES-D scale: A self-report depression scale for research in the general population. Applied Psychological Measurement, 1(3), 385-401.

Stith, S. M., Smith, D. B., Penn, C. E., Ward, D. B., \& Tritt, D. (2004). Intimate partner physical abuse perpetration and victimization risk factors: A meta-analytic review. Aggression and Violent Behavior, 10, 65-98. https://doi.org/10.1016/j. avb.2003.09.001

Straus, M. A. (2004). Scoring the CTS2 and CTSPC. University of New Hampshire.

Straus, M. A., Hamby, S. L., Boney-McCoy, S., \& Sugarman, D. B. (1996). The revised Conflict Tactics Scale (CTS2): Development and preliminary psychometric data. Journal of Family Issues, 17(3), 283-316. https://doi. org/10.1177/019251396017003001

Turney, K. (2014). The consequences of paternal incarceration for maternal neglect and harsh parenting. Social Forces, 92(4), 1607-1636. https://doi.org/10.1093/ sf/sot 160

Turney, K., \& Halpern-Meekin, S. (2017). Parenting in on/off relationships: The link between relationship churning and father involvement. Demography, 54, 861886. https://doi.org/10.1007/s13524-017-0571-5

Ward, K. P., \& Lee, S. J. (2020). Mothers' and fathers' parenting stress, responsiveness, and child wellbeing among low-income families. Children and Youth Services Review, 116, 105218.

Warmuth, K. A., Cummings, E. M., \& Davies, P. T. (2020). Constructive and destructive interparental conflict, problematic parenting practices, and children's symptoms of psychopathology. Journal of Family Psychology, 34, 301-311. https:// doi.org/10.1037/fam0000599

Webster-Stratton, C., \& Hammond, M. (1999). Marital conflict management skills, parenting style, and early-onset conduct problems: Processes and pathways. The Journal of Child Psychology and Psychiatry and Allied Disciplines, 40(6), 917-927.

Wood, R. G., Moore, Q., Clarkwest, A., Hsueh, J., \& McConnell, S. (2010). Strengthening unmarried parents' relationships: The early impacts of Building Strong Families [Technical supplement]. Mathematica Policy Research. 
Wood, R. G., Moore, Q., Clarkwest, A., Killewald, A., \& Monahan, S. (2012). The long-term effects of Building Strong Families: A relationship skills education program for unmarried parents [Final report]. Mathematica Policy Research.

\section{Author Biographies}

Shawna J. Lee, PhD, is an associate professor at the School of Social Work, University of Michigan, Ann Arbor. She is the director of the Parenting in Context Research Lab. Her research interests include father-child relationships, child maltreatment prevention, and child well-being.

Garrett T. Pace, MSW, is a doctoral student at the Joint PhD program in Social Work and Sociology, University of Michigan, Ann Arbor. His research interests include inequality, family relationships, and child well-being.

Joyce Y. Lee, MS, MSW, is a doctoral candidate at the Joint PhD program in Social Work and Psychology, University of Michigan, Ann Arbor. Her research focuses on family processes, with an emphasis on father involvement, that promote child development and well-being.

Inna Altschul, $\mathrm{PhD}$, is an associate professor at the Graduate School of Social Work, University of Denver. Her research focuses on family processes that support positive youth and child development, with a specific focus on low-income, diverse families. 